NASA/TM-2006-214352

\title{
Procedure for Separating Noise Sources in Measurements of Turbofan Engine Core Noise
}

Jeffrey Hilton Miles

Glenn Research Center, Cleveland, Ohio 


\section{NASA STI Program . . . in Profile}

Since its founding, NASA has been dedicated to the advancement of aeronautics and space science. The NASA Scientific and Technical Information (STI) program plays a key part in helping NASA maintain this important role.

The NASA STI Program operates under the auspices of the Agency Chief Information Officer. It collects, organizes, provides for archiving, and disseminates NASA's STI. The NASA STI program provides access to the NASA Aeronautics and Space Database and its public interface, the NASA Technical Reports Server, thus providing one of the largest collections of aeronautical and space science STI in the world. Results are published in both non-NASA channels and by NASA in the NASA STI Report Series, which includes the following report types:

- TECHNICAL PUBLICATION. Reports of completed research or a major significant phase of research that present the results of NASA programs and include extensive data or theoretical analysis. Includes compilations of significant scientific and technical data and information deemed to be of continuing reference value. NASA counterpart of peer-reviewed formal professional papers but has less stringent limitations on manuscript length and extent of graphic presentations.

- TECHNICAL MEMORANDUM. Scientific and technical findings that are preliminary or of specialized interest, e.g., quick release reports, working papers, and bibliographies that contain minimal annotation. Does not contain extensive analysis.

- CONTRACTOR REPORT. Scientific and technical findings by NASA-sponsored contractors and grantees.
- CONFERENCE PUBLICATION. Collected papers from scientific and technical conferences, symposia, seminars, or other meetings sponsored or cosponsored by NASA.

- SPECIAL PUBLICATION. Scientific, technical, or historical information from NASA programs, projects, and missions, often concerned with subjects having substantial public interest.

- TECHNICAL TRANSLATION. Englishlanguage translations of foreign scientific and technical material pertinent to NASA's mission.

Specialized services also include creating custom thesauri, building customized databases, organizing and publishing research results.

For more information about the NASA STI program, see the following:

- Access the NASA STI program home page at http://www.sti.nasa.gov

- E-mail your question via the Internet to help@sti.nasa.gov

- Fax your question to the NASA STI Help Desk at 301-621-0134

- Telephone the NASA STI Help Desk at 301-621-0390

- Write to:

NASA STI Help Desk

NASA Center for AeroSpace Information 7121 Standard Drive Hanover, MD 21076-1320 
NASA/TM-2006-214352

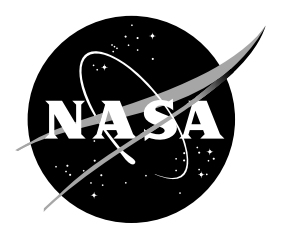

\section{Procedure for Separating Noise Sources in Measurements of Turbofan Engine Core Noise}

Jeffrey Hilton Miles

Glenn Research Center, Cleveland, Ohio

Prepared for the

12th Aeroacoustics Conference

cosponsored by the American Institute of Aeronautics and Astronautics

and Confederation of European Aerospace Societies

Cambridge, Massachusetts, May 8-10, 2006

National Aeronautics and

Space Administration

Glenn Research Center

Cleveland, Ohio 44135 
Trade names and trademarks are used in this report for identification only. Their usage does not constitute an official endorsement, either expressed or implied, by the National Aeronautics and Space Administration.

This work was sponsored by the Fundamental Aeronautics Program at the NASA Glenn Research Center.

Level of Review: This material has been technically reviewed by technical management.

Available from

NASA Center for Aerospace Information 7121 Standard Drive

Hanover, MD 21076-1320
National Technical Information Service 5285 Port Royal Road Springfield, VA 22161 


\title{
Procedure for Separating Noise Sources in Measurements of Turbofan Engine Core Noise
}

\author{
Jeffrey Hilton Miles \\ National Aeronautics and Space Administration \\ Glenn Research Center \\ Cleveland, Ohio 44135
}

\begin{abstract}
The study of core noise from turbofan engines has become more important as noise from other sources like the fan and jet have been reduced. A multiple microphone and acoustic source modeling method to separate correlated and uncorrelated sources has been developed. The auto and cross spectrum in the frequency range below $1000 \mathrm{~Hz}$ is fitted with a noise propagation model based on a source couplet consisting of a single incoherent source with a single coherent source or a source triplet consisting of a single incoherent source with two coherent point sources. Examples are presented using data from a Pratt and Whitney PW4098 turbofan engine. The method works well.
\end{abstract}

\section{Nomenclature}

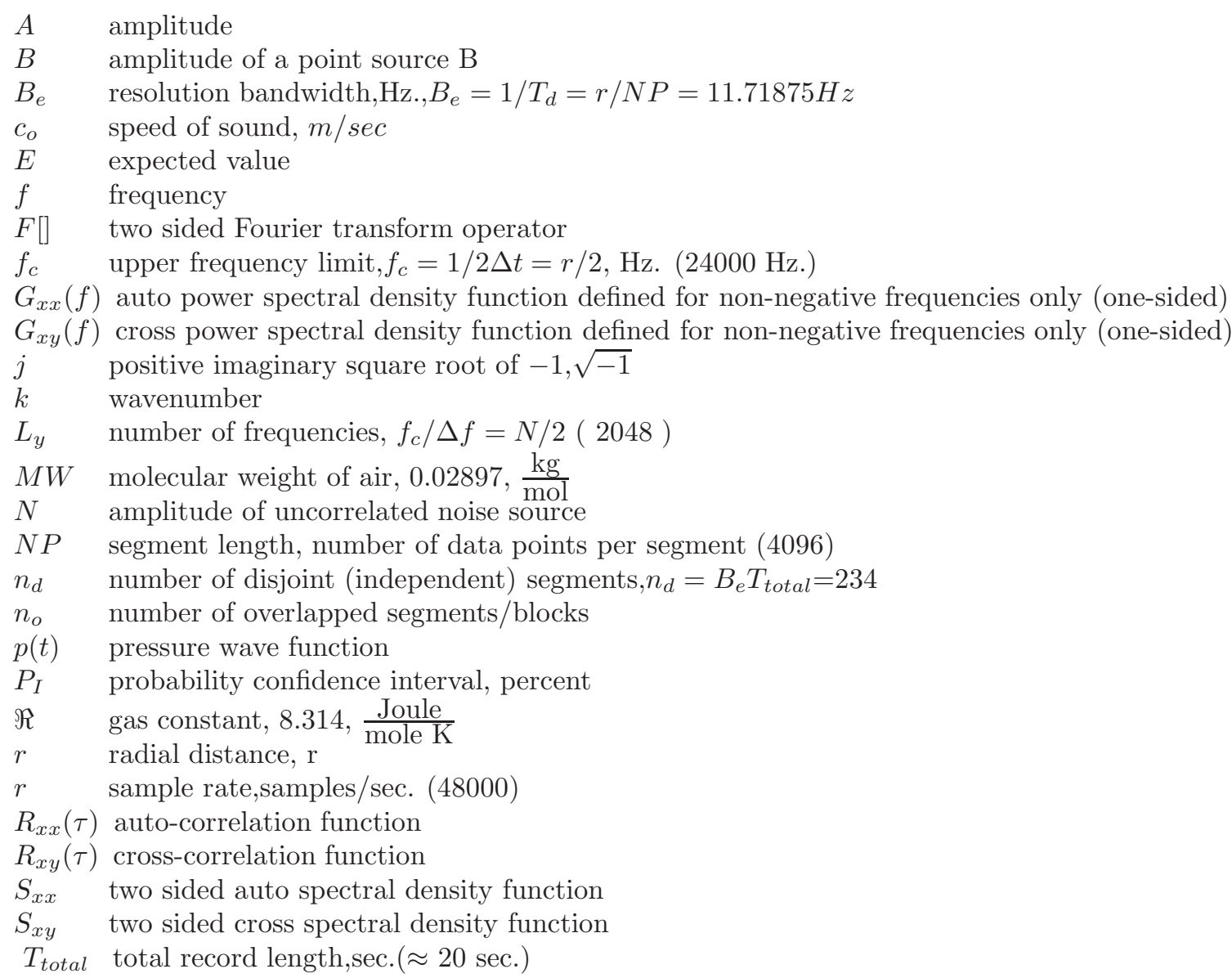


$t$ time, sec.

$T_{d} \quad$ record length of segment

$T F \quad$ air temperature degrees Fahrenheit $\left(80^{\circ}\right)$

$T K$ temperature in degrees Kelvin

$X(f)$ two sided Fourier transform

$X_{\theta}(i, f)$ one sided Fourier transform of block i

Subscripts

o some arbitrary specific value

$x \quad$ signal $\mathrm{x}$

$y \quad$ signal $\mathrm{y}$

Symbols

$\Delta f \quad$ frquency step, $1 / T_{d}, \mathrm{~Hz}$. (11.718)

$\Delta t \quad$ sampling interval, $1 / r(1 / 48000)$,sec.

$\delta \quad$ dirac delta function

$\gamma \quad$ ratio of specific heats, 1.4

$\gamma_{n n}^{2}(f)$ magnitude squared coherence (MSC) function of noise

$\gamma_{x y}^{2}(f)$ magnitude squared coherence (MSC) function

$\tau \quad$ time displacement, sec.

$\tau_{1} \quad$ propagation time delay

\section{Introduction}

Understanding turbofan engine noise is a key priority of the National Aeronautics and Space Administration (NASA). Consequently, new diagnostic procedures to identify dominant sources and changes in dominant sources are being developed. This paper discusses a new diagnostic procedure that separates correlated far field turbofan noise from uncorrelated farfield turbofan noise using a multiple microphone method and point source acoustic models. The auto and cross spectrum in the frequency range below $1000 \mathrm{~Hz}$ is fitted with a noise propagation model based on a source couplet consisting of a single incoherent source with a single coherent source or a source triplet consisting of a single incoherent source with two coherent point sources. Two noise signals are coherent if they can be aligned with one another so that the coherence calculated using a periodogram averaging method is greater than the coherence of two random signals using the same periodogram averaging method. As fan noise and jet noise from turbofan engines are reduced, the issue of core noise reduction becomes more important. While core noise may be reduced by acoustic liners, the issue of measuring the amount of reduction becomes increasingly important. The proposed scheme separates coherent noise from random jet noise and should enable the measurement of the effectiveness of core noise reduction liners. The scheme was developed as part of a research program to study core noise from a Pratt \& Whitney PW4098 turbofan engine ( Miles. ${ }^{1-3}$ )

Procedures using coherence-based techniques have been developed for extracting acoustic signals buried in noise. The coherent output power method for noise source identification is discussed in by Bendat. ${ }^{4-6}$ The application of this technique that is of interest is the use of coherent output power spectra to separate and identify correlated combustion noise in far field measurements of turbofan engine noise. Karchmer ${ }^{7}$ and Karchmer, Reshotko, and Montegani, ${ }^{8}$ use the coherence function calculated from internal microphone measurements of fluctuating pressures in the combustor and far field acoustic pressures to determine the correlated combustion noise of a YF102 turbofan engine at far field locations by calculating the coherent output power spectrum.

The three signal coherence technique was developed by Chung ${ }^{9,10}$ for flow noise rejection. A similar technique was developed and used by Krejsa. ${ }^{11}$ The three signal coherence technique was used by Shivashankara $^{12}$ to study core noise in a Pratt and Whitney JT9D. It was used by Hsu and Ahuja ${ }^{13}$ to separate ejector internal mixing noise from far field measurements and by Stoker, Ahuja, and Hsu ${ }^{14}$ to separate wind-tunnel background noise and wind noise from automobile interior noise measurements. It was used by Michalke, Arnold and Holste ${ }^{15}$ to study sound in a circular duct with mean flow. The method is also discussed by Minami and Ahuja. ${ }^{16}$

The inherent coherent properties of jet and core noise have been used in several source separation procedures. The radiated field of jet noise is has a low coherence when measured at two widely separated points. 
Parthasarathy ${ }^{17}$ attributes this to the fact that the jet noise sources are in motion so that the source frequencies undergo large Doppler shifts as the noise is radiated to the far field. Core noise has a high coherence when measured at two widely separated points. This is attributed to the fact that the frequencies of the radiated core noise are preserved unchanged in the far field Parthasarathy. ${ }^{17}$ Consequently, three signal coherence technique is especially useful to study turbofan core noise using widely spaced microphones.

A method of separating jet noise and core noise using auto-correlations and cross-correlations was developed by Parthasarathy. ${ }^{17}$ The model presented assumes the microphones are located on the arc of a circle about a single source having a known position. This is a couplet source which produces a core noise sound radiation field that is correlated over wide microphone spacing and a jet noise sound radiation field that is not correlated over wide microphone spacing. Since the microphones are on the same arc, the model crosscorrelations calculated have zero propagation time delay. In addition, a model for the jet noise directivity is used. The resulting system of three unknowns and three equations can be solved exactly. In applying this method to data from a small jet the source location is known and a correction to the amplitude correlation measurements is made so that the microphones are located on the arc of a circle about a source having a known position. In applying this method to measured data, I assume the cross-correlations were also time shifted to remove the propagation time delay. An extension of the method to obtain spectral information is also discussed using non zero values of propagation time delay. The phase angle shift due to propagation time delay is not discussed. Again, this seems to indicate that the propagation time delay is being set to zero. The method calculates the jet noise spectrum, the core noise spectrum, and the directivity ratio of the core noise at a particular angle as a function of frequency from measured auto and cross spectra. The method was applied to experimental data obtained in a small scale facility. The spectral formulation of this method was used by Tessson ${ }^{18,19}$ to study jet noise and core noise from the static test of a small gas turbine engine in an anechoic chamber.

A method to achieve separation of two different correlated noise sources from far field measurements contaminated by extraneous jet noise using multiple microphones was developed by Minami and Ahuja. ${ }^{16}$ The equations discussed use measured auto-spectra and cross-spectra. The model assumes the source noise can be represented by a triplet consisting of a correlated noise source A, correlated noise source B, and an uncorrelated noise source. I assume that all the sources are at a single triplet location however in the formulation presented no source location or microphone location information is used. The five microphone method described involves solving a set of 55 equations for 55 unknowns at each frequency of interest. At each microphone location the spectrum of correlated noise source A, correlated noise source B, and an uncorrelated noise source is obtained as a function of frequency. The method was validated using analytical simulations.

The method presented herein also models the auto- and cross- spectrum measurements made with multiple microphones. The method uses a point source propagation model so the microphones need not be on an arc. As a consequence, the directivity is the same in each direction for each source. The method assumes the engine noise source can be modeled with a source doublet or triplet. One part source doublet and triplet consists of an incoherent source at the location taken as $x=0.0$ and $y=0.0$. The source doublet has an additional coherent source at location $x=x_{A}$ with $y=0.0$. The source triplet has two additional coherent sources at location $x=x_{A}$ with $y=0.0$ and $x=x_{B}$ with $y=0.0$. As part of the procedure a comparison of results obtained with the use of a source couplet with the results obtained using a source triplet is made. In addition, a source position is assumed to have a y coordinate of zero and the $\mathrm{x}$ coordinate along the engine axis is found as a function of frequency. This is done since noise can be radiated from the engine case to the far field as well as from the nozzle. In order to solve the resulting acoustic equations for a small set of parameters, a solution method that provides an optimum solution in a least square sense without derivatives was used. The method is set up to do a least squares curve fit to match the auto-spectra and the cross spectra magnitude and phase measurements between all microphones. The method assumes the existence of one or more point sources that can produce the same measurements. The problem then becomes one of finding the appropriate point sources. The current strategy is to have the curve fit adjust the amplitude and $\mathrm{x}$ location of the sources that determine the cross spectrum at each microphone and the amplitude of a random noise source. For the single coherent source case, three parameters are found at each frequency. When a model with two coherent sources is used, one has five parameters to determine at each frequency. Examples are presented calculated with a four microphone array using data from a Pratt and Whitney PW4098 turbofan engine. 


\section{PW4098 Engine at C-11 Stand for EVNRC Phase 2 Tests}

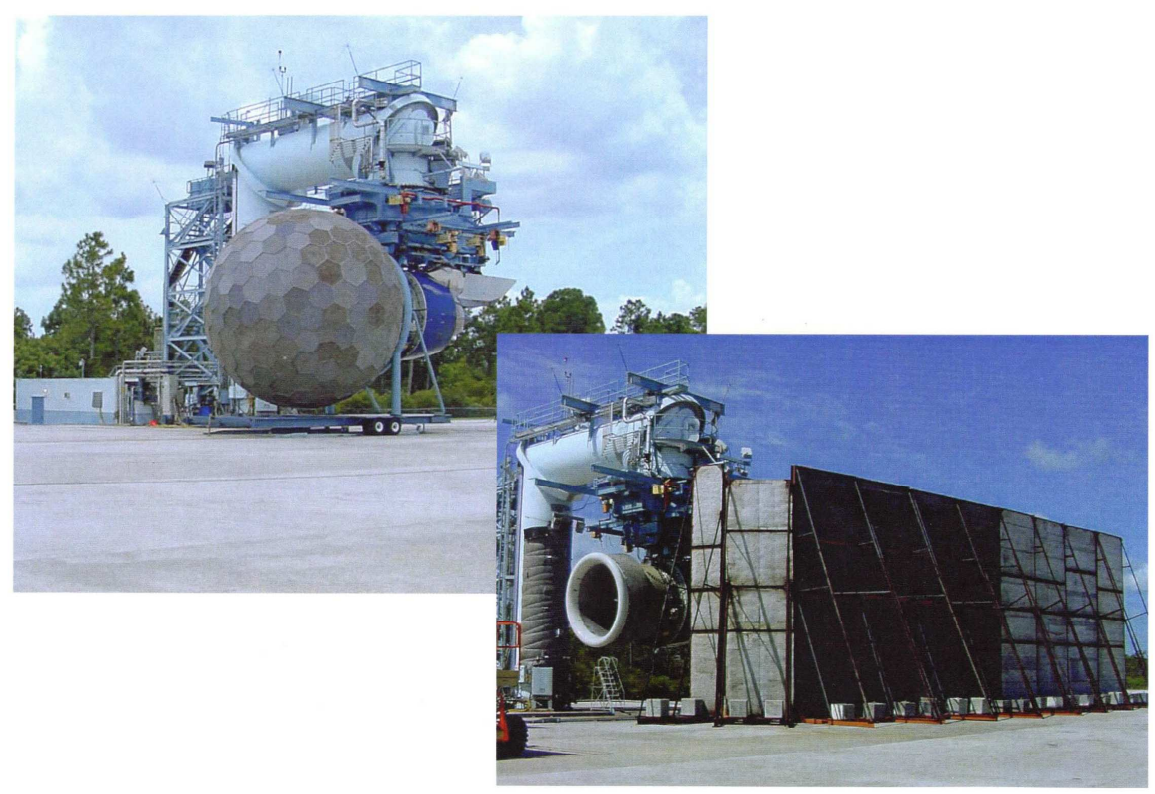

Figure 1. Pratt \& Whitney test stand C11, West Palm Beach Florida, with PW4098 engine and attached acoustic inflow control device also with and without aft acoustic barrier walls for EVNRC Phase 2 tests. 


\section{Analysis Method}

The core noise is assumed to be propagating in acoustic modes in the turbofan engine. The coherent acoustic energy leaves the nozzle and travels through the turbofan engine shear layer to a ground microphone. Additional acoustic energy from the jet and from random scattering reaches the same microphone. In this test program four microphones at 150 feet and angular position of $100^{\circ}, 110^{\circ}, 120^{\circ}$ and $130^{\circ}$ measured from the inlet were used. Consequently, the measurements available at each test condition are four sound pressure spectrums and six sound pressure cross-spectrums each consisting of a magnitude and a phase angle. These sixteen measurements are available as a function of frequency. Four real variable and six complex variable acoustic equations relate the measurements and the model parameters. The angular separation of at least 10 degrees means that the jet noise measured at any microphone can be assumed to be incoherent with the jet noise at any another microphone.

The basic procedure is to assume that some combination of coherent sources and an incoherent source will produce the measured auto and cross spectra. The coherent source is assumed to be on the turbofan engine centerline as some $x$ position to be determined with $y=0$. The incoherent source is assumed to be at $x=0$ and $y=0$. Using the results in appendix A on page 11 where the onesided spectrum functions for acoustic signals from a point source are derived, the acoustic model equations shown in appendix B through E are defined.

Figure 2. Acoustic arena and microphone array at Pratt \& Whitney test stand C11, West Palm Beach Florida for EVNRC Phase 2 tests. The following models were considered.

- Two parameter model. Coherent source of magnitude A at $\left(x=x_{a}, y=0\right)$ (Appendix B on page 12 ).

- Three parameter model. Coherent source of magnitude A at $\left(x=x_{a}, y=0\right)$ (Appendix $\mathrm{C}$ on page 13). with an incoherent source of magnitude $\mathrm{N}$ at $(x=0, y=0)$

- Four parameter model. Coherent source of magnitude A at $\left(x=x_{a}, y=0\right)$ and a Coherent source of magnitude $\mathrm{B}$ at $\left(x=x_{b}, y=0\right)$ (Appendix $\mathrm{D}$ on page 13 ).

- Five parameter model. Coherent source of magnitude A at $\left(x=x_{a}, y=0\right)$ and Coherent source of magnitude $\mathrm{B}$ at $\left(x=x_{b}, y=0\right)$ with an incoherent source of magnitude $\mathrm{N}$ at $(x=0, y=0)$ (Appendix E on page 13)

Consequently, the number of equations greatly exceeds the number of model parameters used in the study discussed herein. Note that no radiation pattern is assumed for these models. These are point sources that radiate sound equally in all directions.

The measured auto-spectrum and cross-spectrum required as input to the acoustic model equations is experimentally determined and subject of nominal experimental error and statistical uncertainties. Also, the measured auto-spectrum includes random noise in addition to coherent signals from propagating waves. Consequently, a solution method that provides an optimum solution in a least squares sense without derivatives was used. Algorithms for minimization without derivatives are discussed by Brent. ${ }^{20}$ The search technique used in this study is described by Powell ${ }^{21}$ and Fortran computer code for this algorithm is given by Shapiro ${ }^{22}$ and Kuester. ${ }^{23}$ The code used was a modified version of the one in Shapiro ${ }^{22}$ which was updated to be in a FORTRAN 90 style. The cost function used is written in terms of sound pressure level and phase angle. 


\section{Experiment}

To demonstrate the usefulness of the procedure for separating correlated and uncorrelated noise sources measurements made in the far field of a Pratt \& Whitney PW4098 turbofan engine will be used. The measurements were made in a study of aircraft turbofan engine core noise conducted as part of the NASA Engine Validation of Noise Reduction Concepts (EVNRC) Program.

The spectral estimate parameters are shown in table 1 on the next page The signal processing algorithms used were written in Fortran. They are based on subprogram modules developed by Stearns and David. ${ }^{24}$ In the calculations the segments were overlapped by 50 percent. Fig. 1 on page 4 shows the test stand. Fig. 2 on the page before shows the angular placement of the far field microphones on a 150 foot radius. This analysis uses the microphones at $100^{\circ}, 110^{\circ}, 120^{\circ}$ and $130^{\circ}$ measured from the inlet. The coordinate system used herein has the $x$ axis along the engine centerline increasing to the right. The $y$ axis is perpendicular and increases toward the top of the page. The center $(x=0, y=0)$ is at the engine center.

\section{Results}

\section{A. Cross-Spectra Validity}

The signals from each pair of microphones used to calculate the cross-spectra only produce valid measurements if the coherence is greater than some threshold coherence. The coherence function is given by

$$
\gamma_{\theta_{1} \theta_{2}}^{2}(f)=\frac{\left|G_{\theta_{1} \theta_{2}}(f)\right|^{2}}{G_{\theta_{1} \theta_{1}}(f) G_{\theta_{2} \theta_{2}}(f)}
$$

The measured coherence calculated using segments overlapped by $50 \%$ is given by

$$
\hat{\gamma}_{\theta_{1} \theta_{2}}^{2}(f)=\frac{\left|\sum_{i=1}^{n_{o}} X_{\theta_{1}}^{*}(i, f) X_{\theta_{2}}(i, f)\right|^{2}}{\sum_{i=1}^{n_{o}}\left|X_{\theta_{1}}(i, f)\right|^{2} \sum_{i=1}^{n_{o}}\left|X_{\theta_{2}}(i, f)\right|^{2}}
$$

In Miles ${ }^{1}$ comparisons were made of a coherence threshold based on aligned and unaligned coherence and one based an analytical coherence threshold using computer simulation. Results were obtained from computer simulation that show good agreement with the theoretical estimate of the analytical coherence threshold

$$
\gamma_{n n}^{2}=1-(1-P)^{1 /\left(n_{d}-1\right)}
$$

where we use herein $P=0.95$ and instead of the number of independent segments/blocks $n_{d}$ we take $n_{d}=n_{o}$ where $n_{o}$ is the number of overlapped segments/blocks. The coherence threshold $\gamma_{n n}^{2}$ is discussed by Carter, ${ }^{25,26}$ Halliday et. al. ${ }^{27}$ (page 247), and Brillinger ${ }^{28}$ (page 317). The coherence threshold $\gamma_{n n}^{2}$ has a value which is greater than $95 \%$ of the values of the coherence of two independent time series calculated using $n_{d}$ disjoint data segments/blocks. The coherence threshold used herein is calculated using the number of overlapped segments, $n_{o}$. As part of the set of figures for each case used to show the results, the coherence and the threshold coherence, $\gamma_{n n}^{2}$, will also be shown. The data used herein had coherence values above the threshold coherence, $\gamma_{n n}^{2}$.

\section{B. Cross-Spectra Phase Angle Sampling Errors}

In Bendat ${ }^{6}$ and in Piersol $^{29}$ the random error in the phase estimates due to statistical sampling is given in terms of the standard deviation of the estimated phase angle, $\hat{\theta}_{12}$, by

$$
\sigma\left[\hat{\theta}_{12}(f)\right] \approx \sin ^{-1}\left\{\frac{\left[1-\gamma_{12}^{2}(f)\right]^{1 / 2}}{\left|\gamma_{12}\right| \sqrt{2 n_{o}}}\right\}
$$

where $\sigma\left[\hat{\theta}_{12}(f)\right]$ is measured in radians and as used herein $n_{o}$ is selected to be the number of overlapped segments or blocks used in the spectral calculations. For the special case where the term in curly brackets is small Eq. 4 becomes 


$$
\sigma\left[\hat{\theta}_{12}(f)\right] \approx \frac{\left[1-\gamma_{12}^{2}(f)\right]^{1 / 2}}{\left|\gamma_{12}\right| \sqrt{2 n_{o}}}
$$

where for the unknown coherence $\gamma_{12}^{2}(f)$ the estimated coherence $\hat{\gamma}_{\theta_{1} \theta_{2}}^{2}(f)$ from Eq. 2 is used. A plot of the standard deviation of the phase angle in degrees verses coherence is shown in 3 on page 10.

When the coherence is greater than 0.15, Fig. 3 shows the standard deviation should be less than 5 degrees. Straight line fits was made to the phase verses frequency data. The standard deviation of the error was greater than on would calculate from the coherence i.e around 10 degrees when one calculated 5 degrees. Consequently, the phase angle measurements might be showing propagation effects due to wind shear or temperature gradients or a change in source location with frequency. In addition, the error verses frequency plots seemed to be in phase for each pair. As a consequence, instead of a using a fixed source location in the model the $\mathrm{y}$ co-ordinate of a source is fixed at zero and the $\mathrm{x}$ co-ordinate is free to vary.

\section{Point source models}

The method discussed has been tried out over a range of operating conditions. For each case all four models were used. Four typical cases presented herein shown in Fig. 4 on page 14,Fig. 5 on page 15,Fig. 6 on page 16, and Fig. 7 on page 17.are for N1 Corr. values of $582 \mathrm{rpm}, 1622 \mathrm{rpm}, 1900 \mathrm{rpm}$ and $2743 \mathrm{rpm}$. Only one acoustic model result is shown for each case. The selected case uses the fewest number of parameters to achieve a good result. For each case all four auto-spectra and six cross-spectra are calculated. However, only the following items are shown herein:

- The measured and calculated auto-spectrum at 100 degrees.

- The measured and calculated cross-spectrum magnitude between the 100 degree and 120 degree microphones.

- The measured and calculated cross-spectrum phase angle between the 100 degree and 120 degree microphones.

- The measured coherence and analytic threshold coherence between the 100 degree and 120 degree microphones.

- The sound pressure amplitude curve fit parameter or parameters.

- The correlated source location or locations.

In the modeling scheme used herein, for each case the jet noise is assumed to be uncorrelated between the microphones at all frequencies. Furthermore, it is assumed the basic radiation pattern of the correlated noise as specified by the crossspectrum phase angle could be represented by a single point coherent source at some $x$ location. In all cases, a better result is obtained by using an acoustic model which assumes a non correlated noise source is present and letting the computer solution procedure determine if its value is significant. In some cases a second coherent point source gives a slightly better result. Only the coherent sources create the cross spectra. The

Table 1. Spectral Estimate Parameters

\begin{tabular}{|l|l|}
\hline Parameter & value \\
\hline \hline Segment length i.e. Data points per segment, $N P$ & 4096 \\
Sample rate, $r$, samples/second & 48,000 \\
Segment length, $T_{d}=N P / r$, seconds & 0.08533 \\
Sampling interval, $\Delta t=1 / r$, seconds & $2.0833 \times 10^{-5}$ \\
Frequency step, $\Delta f=1 / T_{d}, \mathrm{~Hz}$ & 11.718 \\
Upper frequency limit, $f_{c}=1 / 2 \Delta t=r / 2, \mathrm{~Hz}$ & 24000 \\
number of frequencies, $L y=f_{c} / \Delta f=N P / 2$ & 2048 \\
Time delay, $\tau=6323 / 48000$, seconds & 0.1317 \\
number of independent samples & 234 \\
overlap & 0.50 \\
Sample length,sec. & 20 \\
\hline
\end{tabular}
auto spectra are due to the coherent and incoherent sources.

The general formulation is given in Appendix A on page 11. The general models are shown in Appendix B on page 12 through E on page 13. 


\section{1. $\quad$ N1 Corr $=582 \mathrm{rpm}$}

At the N1 Corr $582 \mathrm{rpm}$ operating condition the core noise is dominated by a low frequency combustion tone at $327 \mathrm{~Hz}$ as shown in Fig. 4a. The core noise radiation pattern is well represented by a single point source as shown in Fig. 4b and Fig. 4c. The results shown are for the three parameter couplet source model $\left(A, N, x_{a}\right)$ described in Appendix $\mathrm{C}$ on page 13. As shown in Fig. 4a, at a few low frequency points the computer solution included a uncorrelated noise source. The coherence shown in Fig. $4 \mathrm{~d}$ is above the coherence threshold $\gamma_{n n}^{2}=0.00639431$. Consequently, the cross spectrum phase angles look good. At most points the uncorrelated noise level was to low to plot as shown in Fig. 4e. As shown in Fig. 4f, in order to match the measured phase angle the computer model puts the source at more than $x_{a}=50$. feet for frequencies less than $200 \mathrm{~Hz}$. and near $x_{b}=20$ feet for frequencies greater than $200 \mathrm{~Hz}$.

\section{2. $\quad$ 1 Corr $=1622 \mathrm{rpm}$}

At the N1 Corr $1622 \mathrm{rpm}$ operating condition, results are shown for the five parameter triplet source model $\left(A, B, N, x_{a}, x_{b}\right)$ described in Appendix $\mathrm{E}$ on page 13. As shown in Fig. 5a this model does a good job below $300 \mathrm{~Hz}$. in representing the 100 degree microphone auto-spectrum and a satisfactory job at higher frequencies. At higher angles the curve fit at these frequencies is better. The core noise radiation pattern is well represented by a two point sources as shown in Fig. 5b and Fig. 5c. Below $300 \mathrm{~Hz}$. this model does a fine job. The coherence shown in Fig. 5d is above the coherence threshold $\gamma_{n n}^{2}=0.00639431$ below $800 \mathrm{~Hz}$. Below $400 \mathrm{~Hz}$. the coherence is grater than 0.15. Consequently, the cross spectrum phase angles look good below $400 \mathrm{~Hz}$. The variation of the two-point model correlated source amplitude shown in Fig. 5e and the source separation results shown in Fig. 5a have the same frequency dependence that the combustion modes have in that they seem to be in $200 \mathrm{~Hz}$ bands. This suggests the correlated noise is due to the combustor source. As shown in Fig. 5f, the source locations of the two point sources have an interesting symmetry. Source B is near $x_{B}=0.0$ and may represent sound radiation from the engine case. Source A is near $x_{A}=25$ and may represent sound radiation from the nozzle.

\section{3. $\quad$ N1 Corr $=1900 \mathrm{rpm}$}

Again, at the N1 Corr $1900 \mathrm{rpm}$ operating condition, results are shown for the five parameter triplet source model $\left(A, B, N, x_{a}, x_{b}\right)$ described in Appendix $\mathrm{E}$ on page 13. As shown in Fig. 6a this model does a good job below $200 \mathrm{~Hz}$. in representing the 100 degree microphone auto-spectrum and a satisfactory job at higher frequencies. At higher angles the curve fit at these frequencies is better. The core noise radiation pattern is well represented by a two point sources as shown in Fig. 6b and Fig. 6c. The coherence shown in Fig. 6d is above the coherence threshold $\gamma_{n n}^{2}=0.00639431$ below $800 \mathrm{~Hz}$. At most points below $800 \mathrm{~Hz}$ the coherence is grater than 0.10. Consequently, the cross spectrum phase angles look good below $800 \mathrm{~Hz}$. The variation of the two-point model correlated source amplitude shown in Fig. 6e and the source separation results shown in Fig. 6a again have the same frequency dependence that the combustion modes have in that they seem to be in $200 \mathrm{~Hz}$ bands. This again suggests the correlated noise is due to the combustor source. Again. as shown in Fig. 6f, the source locations of the two point sources have and interesting symmetry. Source B is again near $x_{B}=0.0$ and may represent sound radiation from the engine case. Source A is again near $x_{A}=25$ and may represent sound radiation from the nozzle.

\section{4. $\quad$ N1 Corr $=2743$ rpm}

The highest power setting examined herein is the N1 Corr. $2743 \mathrm{rpm}$ operating condition. The auto-spectrum at 100 degrees is shown in Fig. 7a. Below $100 \mathrm{~Hz}$. the uncorrelated noise source is not needed to represent the measurements. The core noise radiation pattern is well represented again by a single point source as shown in Fig. 7b and Fig. 7c. The results shown are for the three parameter couplet source model( $\left.A, N, x_{a}\right)$ described in Appendix $\mathrm{C}$ on page 13. As shown in Fig. 7a, at frequencies above $100 \mathrm{~Hz}$. the computer solution included a uncorrelated noise source. The coherence shown in Fig. $7 \mathrm{~d}$ is above the coherence threshold $\gamma_{n n}^{2}=0.00639431$ below $200 \mathrm{~Hz}$. Below $200 \mathrm{~Hz}$. the coherence is above 0.15 . Consequently, the cross spectrum phase angles look good below $200 \mathrm{~Hz}$. Below $100 \mathrm{~Hz}$., the uncorrelated noise level was to low to plot as shown in Fig. 7e. As shown in Fig. 7f, in order to match the measured phase angle the computer model puts the source at more than $x_{A}=30$ feet for frequencies less than $100 \mathrm{~Hz}$. and less than $x_{A}=30$ feet for frequencies greater than $100 \mathrm{~Hz}$. 


\section{Discussion}

These results show how important it is to start with no preconceived idea of what acoustic source mode best represents the measured turbojet core noise. One should use a model that best fits the data and not ones idea of the model. The results show the uncorrelated noise source is not important at frequencies less than $800 \mathrm{~Hz}$ at these angles. Furthermore, the results show that core noise dominates at frequencies less than $800 \mathrm{~Hz}$ at these angles. Furthermore, at many operating points, the sound radiation field can be attributed to two coherent core noise sources. The results indicate that one might be the engine case while the other is the nozzle. The variation of the two-point model correlated source amplitude shown in Fig. 4d and the source separation results shown in Fig. 4a have the same frequency dependence that the combustion modes have in that they seem to be in $200 \mathrm{~Hz}$ bands. This suggests the correlated noise is due to the combustor source. The variation of the two-point model correlated source amplitude shown in Fig. 5d and the source separation results shown in Fig. 5a have the same frequency dependence that the combustion modes have in that they seem to be in $200 \mathrm{~Hz}$ bands. This again suggests the correlated noise is due to the combustor source. Note however, that the cross-spectrum phase angle measurements shown in Figs $4 \mathrm{c}$ and $5 \mathrm{c}$ have a lot of dispersion. The need to satisfy this dispersion may be causing the two correlated source with uncorrelated noise five parameter model to perform better than single correlated source with noise three parameter model. Consequently, further studies need to be done to resolve this issue.

\section{Conclusions}

A new method to separate correlated signals buried in turbofan engine core noise has been presented. The method is based on finding acoustic model coefficients that enable a system of equations based on one or two correlated noise sources and an uncorrelated noise source to reproduce experimental data. The effectiveness and the reliability of the method have been tested using Pratt and Whitney PW4098 far field acoustic

measurements. The agreement achieved between the experimental data and the acoustic model used confirm the effectiveness of the procedure. 


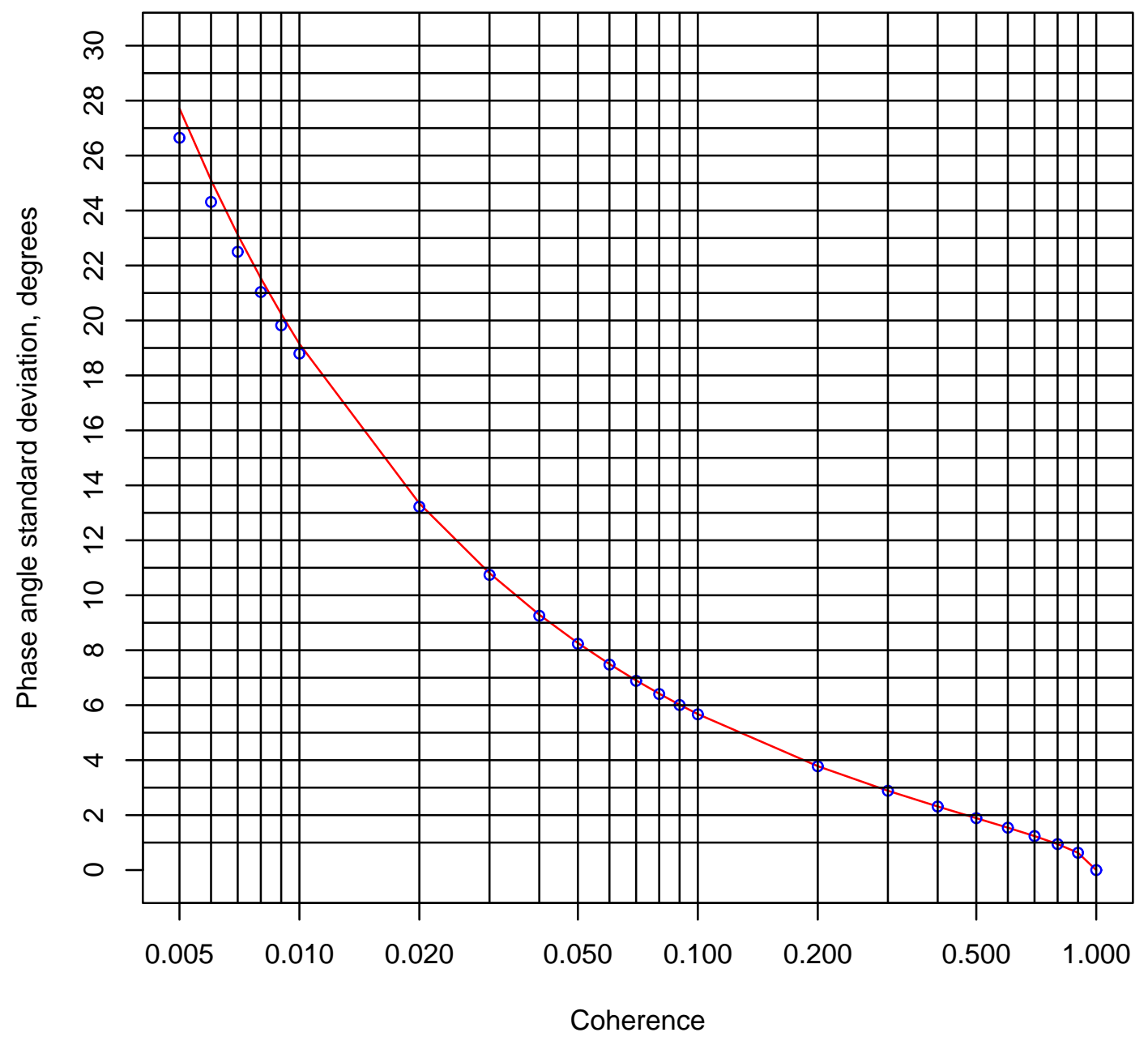

Figure 3. Standard deviation of phase angle of $G_{34}$ based on $\gamma_{34}^{2}$ and $n_{o}$. 


\section{A. One-sided spectrum functions for acoustic signals from a point source}

We shall assume a compact source region and assume the source produces a wave which spreads spherically outward with no preferred direction. The wave equation in this case as discussed by Morse ${ }^{30}$ page 309 is

$$
\frac{1}{r^{2}} \frac{\partial}{\partial r}\left(r^{2} \frac{\partial p}{\partial r}\right)=\frac{1}{c_{o}^{2}} \frac{\partial^{2} p}{\partial t^{2}}
$$

We shall assume a simple source solution to the wave equation $p(t)=\frac{A}{R} \exp (-i k R) \sin \left(2 \pi f_{0} t\right)$ where

$$
\begin{aligned}
k & =\frac{2 \pi f_{0}}{c_{o}} \\
c_{o}^{2} & =\frac{\gamma \Re T K}{M W}, \frac{\mathrm{m}}{\mathrm{sec}} \\
\Re & =8.314, \frac{\mathrm{Joule}}{\mathrm{mole} \mathrm{K}} \\
M W & =0.02897 \frac{\mathrm{kg}}{\mathrm{mol}} \\
T F & =80
\end{aligned}
$$

To get the auto-spectrum and cross-spectrum of a point source we use the following relationships from correlation and spectral analysis texts by Bendat. ${ }^{4-6}$

The autocorrelation function of $x$ is

$$
R_{x x}(\tau)=E\left[x_{k}(t) x_{k}(t+\tau)\right]
$$

The auto correlation function for a sum of two processes $y(t)=x_{1}(t)+x_{2}(t)$ is

$$
\begin{aligned}
R_{y y}(\tau) & =E\left[\left(x_{1}(t)+x_{2}(t)\right)\left(x_{1}(t+\tau)+x_{2}(t+\tau)\right)\right] \\
& =R_{x_{1} x_{1}}(\tau)+R_{x_{1} x_{2}}(\tau)+R_{x_{2} x_{1}}(\tau)+R_{x_{2} x_{2}}(\tau)
\end{aligned}
$$

The two-sided auto and cross spectral density functions are

$$
\begin{aligned}
& S_{x x}(f)=F\left[R_{x x}(\tau)\right]=\int_{-\infty}^{\infty} R_{x x}(\tau) \exp (-j 2 \pi f t) d t \\
& S_{x y}(f)=F\left[R_{x y}(\tau)\right]=\int_{-\infty}^{\infty} R_{x y}(\tau) \exp (-j 2 \pi f t) d t
\end{aligned}
$$

and of course we have the inverse relationships

$$
\begin{aligned}
& R_{x x}(\tau)=F^{-1}\left[S_{x x}(f)\right]=\int_{-\infty}^{\infty} S_{x x}(f) \exp (+j 2 \pi f \tau) d f \\
& R_{x y}(\tau)=F^{-1}\left[S_{x y}(f)\right]=\int_{-\infty}^{\infty} S_{x y}(f) \exp (+j 2 \pi f \tau) d f
\end{aligned}
$$

The two-sided auto spectrum function for a sum of two processes $y(t)=x_{1}(t)+x_{2}(t)$ is

$$
\begin{aligned}
S_{y y}(f) & =F\left[E\left[\left(x_{1}(t)+x_{2}(t)\right)\left(x_{1}(t+\tau)+x_{2}(t+\tau)\right)\right]\right] \\
& =F\left[R_{x_{1} x_{1}}(\tau)+R_{x_{1} x_{2}}(\tau)+R_{x_{2} x_{1}}(\tau)+R_{x_{2} x_{2}}(\tau)\right] \\
& \left.=S_{x_{1} x_{1}}(\tau)+S_{x_{1} x_{2}}(\tau)+S_{x_{2} x_{1}}(\tau)+S_{x_{2} x_{2}}(\tau)\right]
\end{aligned}
$$

The auto-correlation function is the Fourier transform of the correlation of $x(t)$ with itself is related to the Fourier transform of $x(t)$ by 


$$
\begin{aligned}
S_{x x}(f) & =F\left[R_{x x}(\tau)\right]=\int_{-\infty}^{\infty} R_{x x}(\tau) \exp (-j 2 \pi f \tau) d \tau \\
& =X(f) X^{*}(f)
\end{aligned}
$$

The cross-correlation function is the Fourier transform of the correlation of $x(t)$ and $\mathrm{y}(\mathrm{t})$ is related to the Fourier transform of $x(t)$ and $y(t)$ by

$$
\begin{aligned}
S_{x y}(f) & =F\left[R_{x y}(\tau)\right]=\int_{-\infty}^{\infty} R_{x y}(\tau) \exp (-j 2 \pi f \tau) d \tau \\
& =X(f) Y^{*}(f)
\end{aligned}
$$

The one-sided spectral density function is $G_{x}(f)=2 S_{x}(f) 0 \leq f<\infty$.

The auto-correlation function of a sine wave $x(t)=A \cos \left(2 \pi f_{0} t\right)$ is

$$
R_{x x}=\frac{A^{2}}{2} \cos \left(2 \pi f_{0}\right)
$$

The power spectral density of a sine wave $x(t)=A \cos \left(2 \pi f_{0} t\right)$ is

$$
G_{x x}=\frac{A^{2}}{2} \delta\left(f-f_{0}\right)
$$

The one-sided spectrum function for a sum of two processes $y(t)=x_{1}(t)+x_{2}(t)$ is

$$
\left.G_{y y}(f)=G_{x_{1} x_{1}}(\tau)+G_{x_{1} x_{2}}(\tau)+G_{x_{2} x_{1}}(\tau)+G_{x_{2} x_{2}}(\tau)\right]
$$

Next, these relationships are applied to signals produced by acoustic waves from a point source and received at microphone $\mathrm{i}$ and $\mathrm{j}$.

$$
\begin{aligned}
& p_{a_{i}}(t)=\frac{A}{R_{a_{i}}} \exp \left(i k R_{a_{i}}\right) \sin \left(2 \pi f_{0} t\right) \\
& p_{a_{j}}(t)=\frac{A}{R_{a_{j}}} \exp \left(i k R_{a_{j}}\right) \sin \left(2 \pi f_{0} t\right)
\end{aligned}
$$

We have for the one-sided auto spectral density and the one-sided cross spectral density,

$$
\begin{aligned}
G_{p_{a_{i}} p_{a_{i}}} & =\frac{1}{2} \frac{A^{2}}{R_{a_{i}}^{2}} \delta\left(f-f_{0}\right) \\
G_{p_{a_{i}} p_{a_{j}}} & =\frac{1}{2} \frac{A^{2}}{R_{a_{i}} R_{a_{j}}} e^{-j k\left(R_{a_{i}}-R_{a_{j}}\right)} \delta\left(f-f_{0}\right)
\end{aligned}
$$

\section{B. Correlated noise source A}

Consider the i'th and j'th microphones and a single point acoustic source. As shown in Appendix A, the auto spectra are

$$
\begin{aligned}
G_{p_{a_{i}} p_{a_{i}}} & =\frac{1}{2} \frac{A^{2}}{R_{a_{i}}^{2}} \delta\left(f-f_{0}\right) \\
G_{p_{a_{j}} p_{a_{j}}} & =\frac{1}{2} \frac{A^{2}}{R_{a_{j}}^{2}} \delta\left(f-f_{0}\right)
\end{aligned}
$$

and the cross spectrum is

$$
G_{p_{a_{i}} p_{a_{j}}}=\frac{1}{2} \frac{A^{2}}{R_{a_{i}} R_{a_{j}}} e^{-j k\left(R_{a_{i}}-R_{a_{j}}\right)} \delta\left(f-f_{0}\right)
$$




\section{Correlated noise source A and uncorrelated source N}

Consider the i'th and j'th microphones, a single point acoustic source A and a noise source N. As shown in Appendix A, the auto spectra are

$$
\begin{aligned}
G_{p_{a_{i}} p_{a_{i}}} & =\frac{1}{2} \frac{A^{2}}{R_{a_{i}}^{2}} \delta\left(f-f_{0}\right)+\frac{1}{2} \frac{N^{2}}{R_{n_{i}}^{2}} \delta\left(f-f_{0}\right) \\
G_{p_{a_{j}} p_{a_{j}}} & =\frac{1}{2} \frac{A^{2}}{R_{a_{j}}^{2}} \delta\left(f-f_{0}\right)+\frac{1}{2} \frac{N^{2}}{R_{n_{j}}^{2}} \delta\left(f-f_{0}\right)
\end{aligned}
$$

and the cross spectrum is

$$
G_{p_{a_{i}} p_{a_{j}}}=\frac{1}{2} \frac{A^{2}}{R_{a_{i}} R_{a_{j}}} e^{-j k\left(R_{a_{i}}-R_{a_{j}}\right)} \delta\left(f-f_{0}\right)
$$

\section{Correlated noise source A and correlated noise source B}

Consider the i'th and j'th microphones, a point acoustic source A and a point acoustic source B. As shown in Appendix A, the auto spectra are

$$
\begin{aligned}
G_{p_{a_{i}} p_{a_{i}}} & =\frac{1}{2} \frac{A^{2}}{R_{a_{i}}^{2}} \delta\left(f-f_{0}\right)+\frac{1}{2} \frac{B^{2}}{R_{b_{i}}^{2}} \delta\left(f-f_{0}\right) \\
G_{p_{a_{j}} p_{a_{j}}} & =\frac{1}{2} \frac{A^{2}}{R_{a_{j}}^{2}} \delta\left(f-f_{0}\right)+\frac{1}{2} \frac{B^{2}}{R_{b_{j}}^{2}} \delta\left(f-f_{0}\right)
\end{aligned}
$$

and the cross spectrum is

$$
G_{p_{i} p_{j}}=\frac{1}{2} \frac{A^{2}}{R_{a_{i}} R_{a_{j}}} e^{-j k\left(R_{a_{i}}-R_{a_{j}}\right)} \delta\left(f-f_{0}\right)+\frac{1}{2} \frac{B^{2}}{R_{b_{i}} R_{b_{j}}} e^{-j k\left(R_{b_{i}}-R_{b_{j}}\right)} \delta\left(f-f_{0}\right)
$$

\section{E. Correlated noise source A, correlated noise source B, and uncorrelated source $\mathbf{N}$}

Consider the i'th and j'th microphones, a single point acoustic source A and a noise source N. As shown in Appendix A, the auto spectra are

$$
\begin{aligned}
G_{p_{a_{i}} p_{a_{i}}} & =\frac{1}{2} \frac{A^{2}}{R_{a_{i}}^{2}} \delta\left(f-f_{0}\right)+\frac{1}{2} \frac{B^{2}}{R_{b_{i}}^{2}} \delta\left(f-f_{0}\right)+\frac{1}{2} \frac{N^{2}}{R_{n_{i}}^{2}} \delta\left(f-f_{0}\right) \\
G_{p_{a_{j}} p_{a_{j}}} & =\frac{1}{2} \frac{A^{2}}{R_{a_{j}}^{2}} \delta\left(f-f_{0}\right)+\frac{1}{2} \frac{B^{2}}{R_{b_{j}}^{2}} \delta\left(f-f_{0}\right)+\frac{1}{2} \frac{N^{2}}{R_{n_{j}}^{2}} \delta\left(f-f_{0}\right)
\end{aligned}
$$

and the cross spectrum is

$$
G_{p_{i} p_{j}}=\frac{1}{2} \frac{A^{2}}{R_{a_{i}} R_{a_{j}}} e^{-j k\left(R_{a_{i}}-R_{a_{j}}\right)} \delta\left(f-f_{0}\right)+\frac{1}{2} \frac{B^{2}}{R_{b_{i}} R_{b_{j}}} e^{-j k\left(R_{b_{i}}-R_{b_{j}}\right)} \delta\left(f-f_{0}\right)
$$




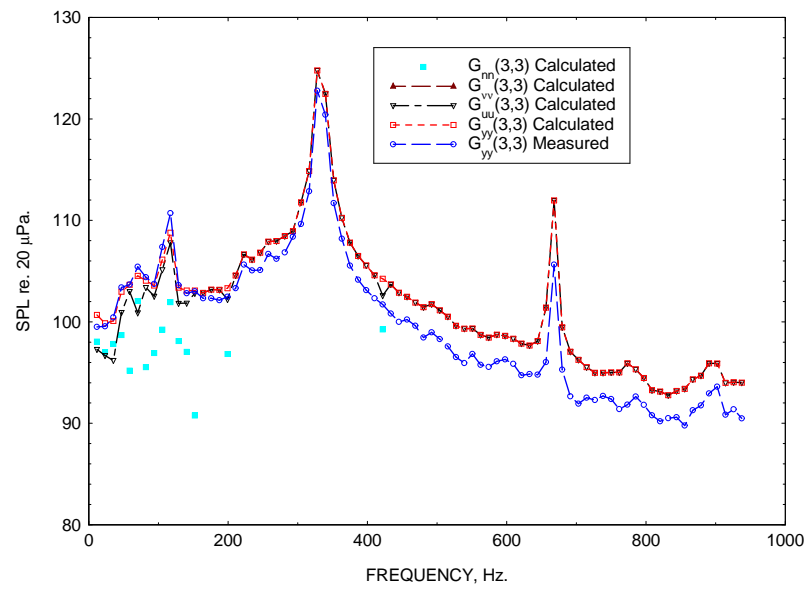

(a) Auto-spectrum 100 Degree microphone at 150 feet using three parameter model.

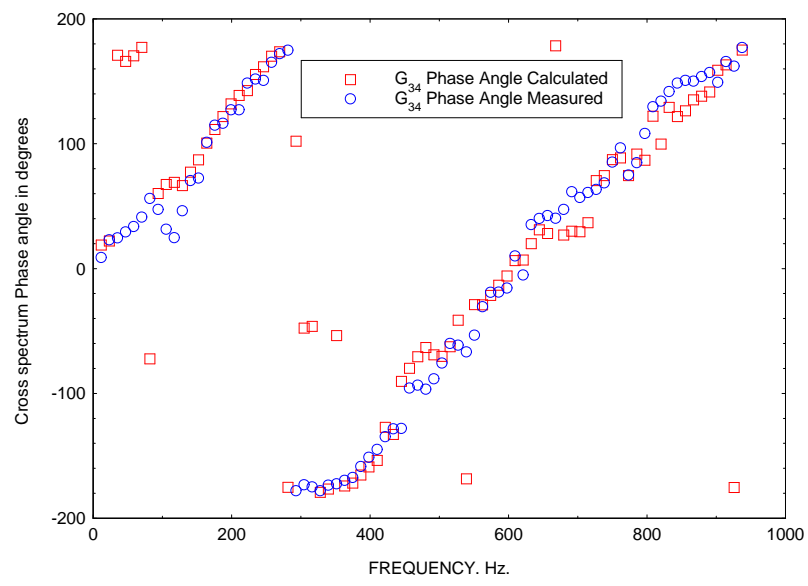

(c) Cross-spectrum phase angle between 100 and 110 Degree microphones at 150 feet using three parameter model

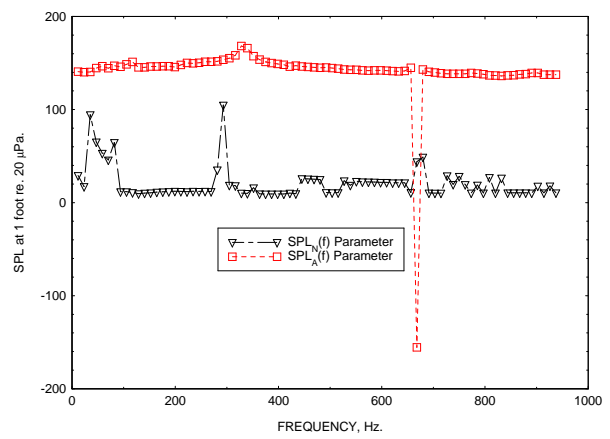

(e) $S P L_{A}$ and $S P L_{N}$ parameters for three parameter model.

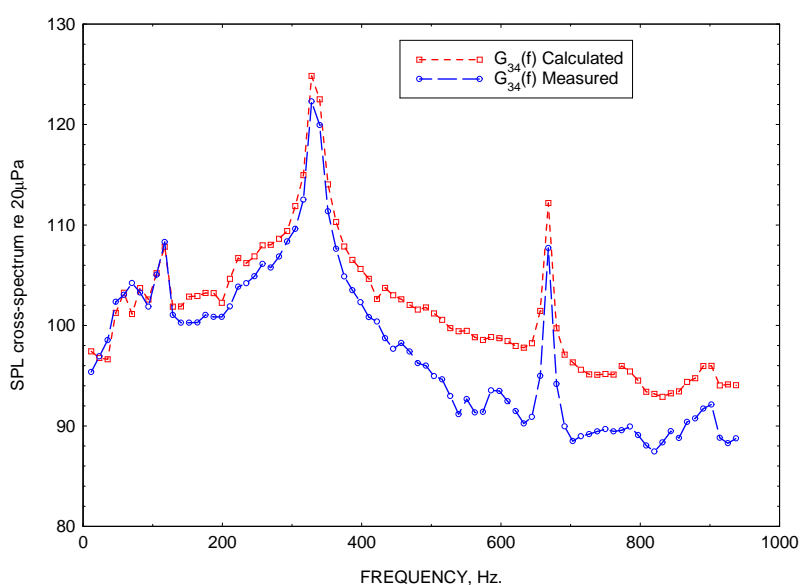

(b) Cross-spectrum magnitude between 100 and 110 Degree microphones at 150 feet using three parameter model.

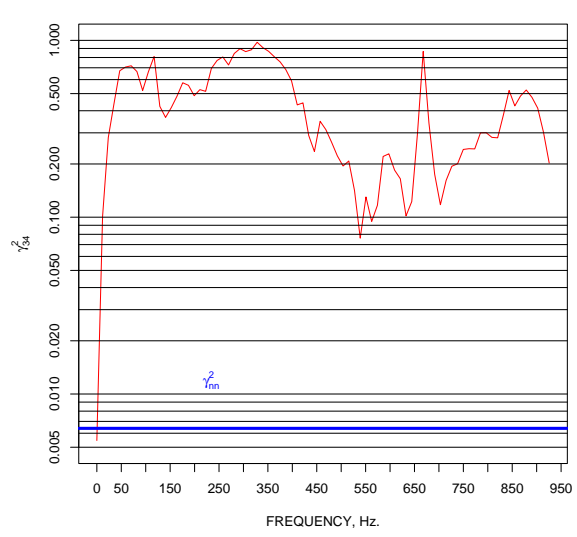

(d) Coherence between 100 and 110 Degree microphones at 150 feet

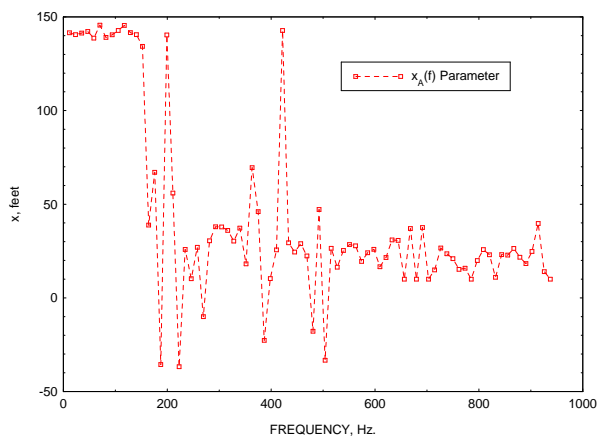

(f) $x_{A}$ location parameter for three parameter model

Figure 4. 582 rpm (N1 Corr.). 


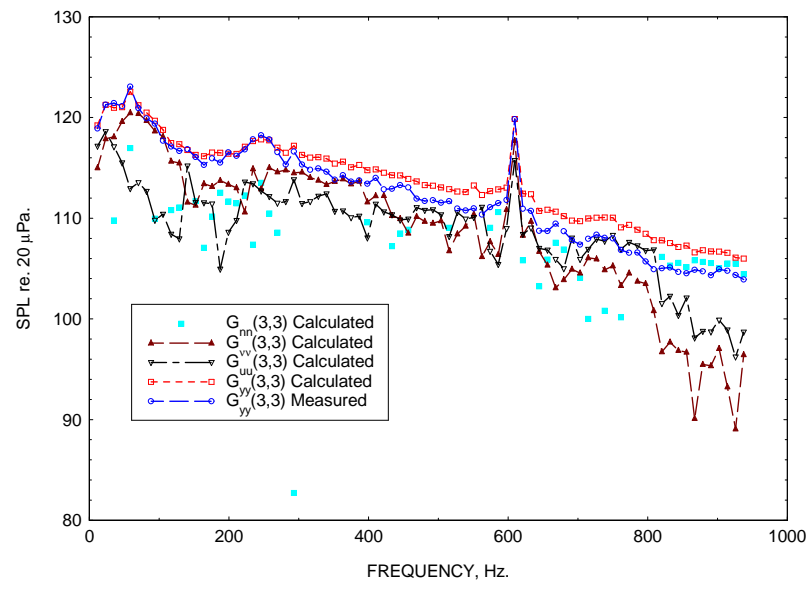

(a) Auto-spectrum 100 Degree microphone at 150 feet using five parameter model.

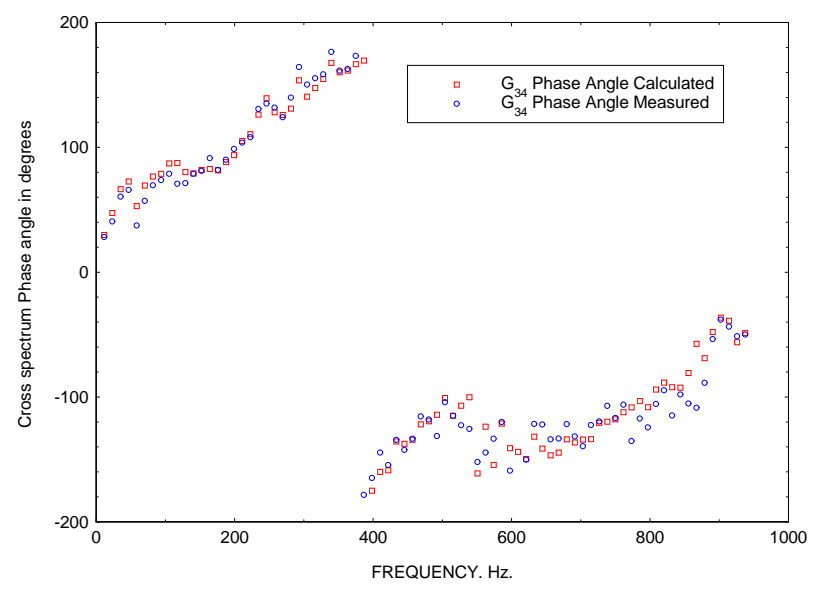

(c) Cross-spectrum phase angle between 100 and 110 Degree microphones at 150 feet using five parameter model.

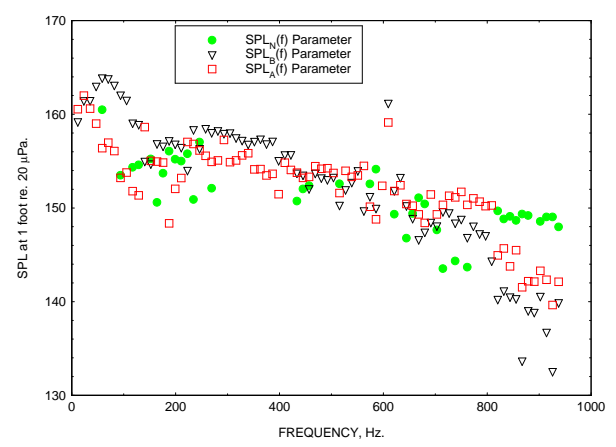

(e) $S P L_{A}, S P L_{B}$ and $S P L_{N}$ parameters for five parameter model.

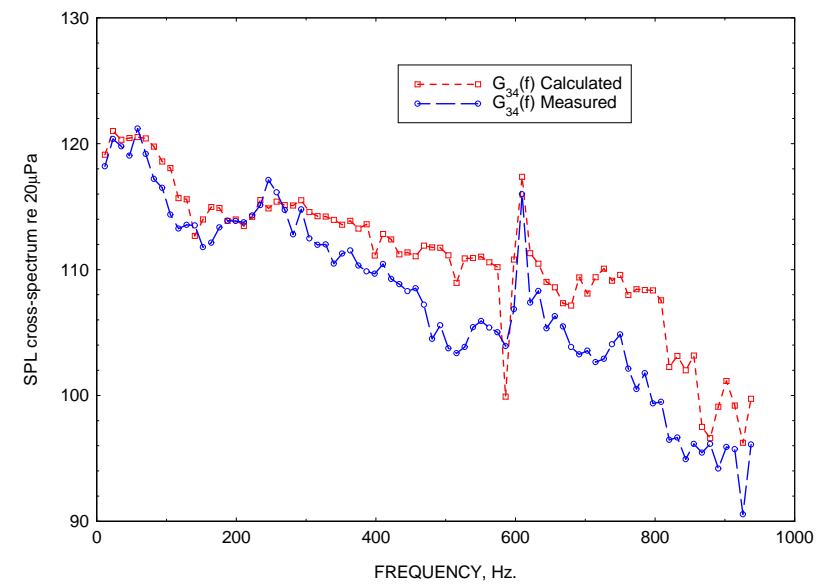

(b) Cross-spectrum magnitude between 100 and 110 Degree microphones at 150 feet using five parameter model.

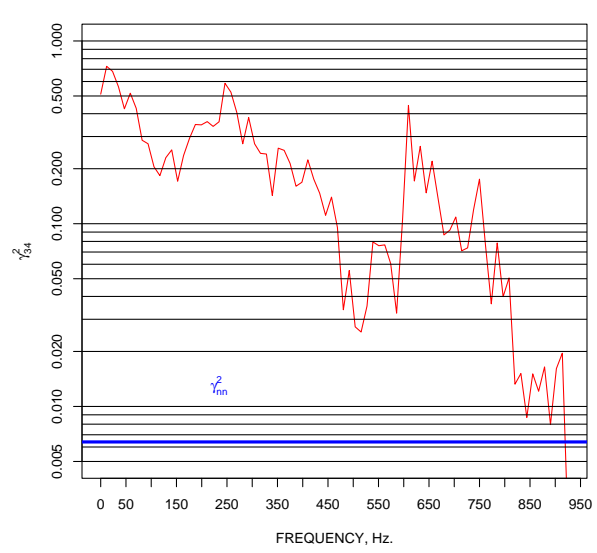

(d) Coherence between 100 and 110 Degree microphones at 150 feet

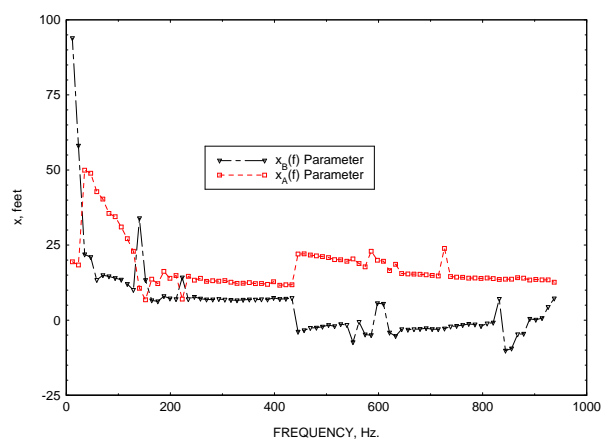

(f) $x_{A}$ location parameter and $x_{B}$ location parameters for five parameter model.

Figure 5. 1622 rpm (N1 Corr.). 


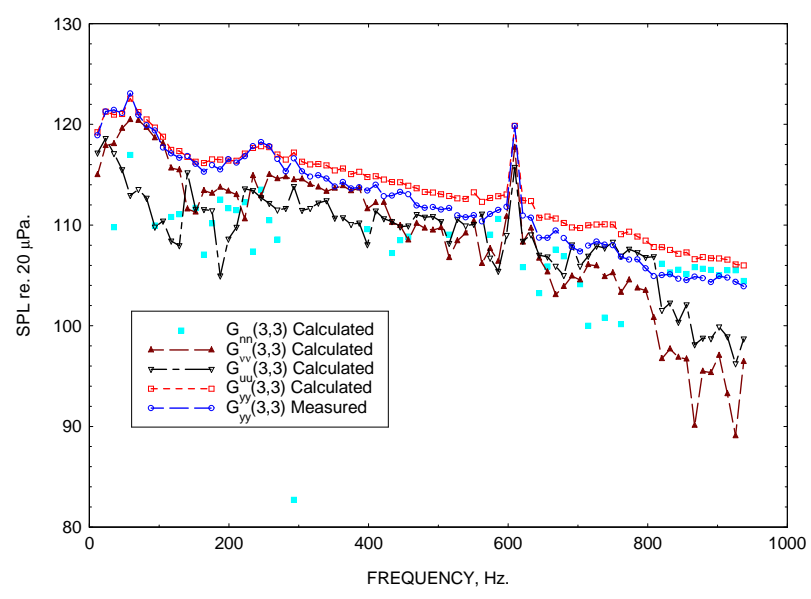

(a) Auto-spectrum 100 Degree microphone at 150 feet using five parameter model.

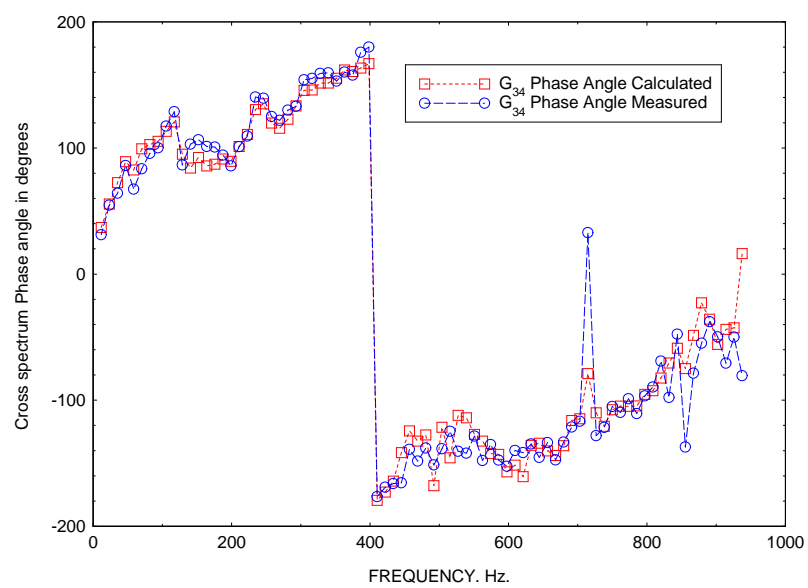

(c) Cross-spectrum phase angle between 100 and 110 Degree microphones at 150 feet using five parameter model.

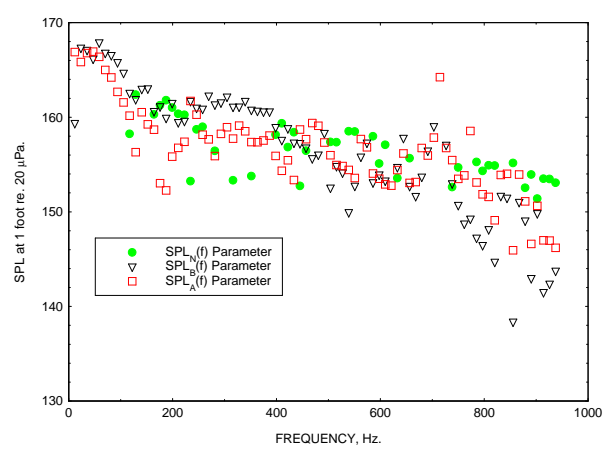

(e) $S P L_{A}, S P L_{B}$ and $S P L_{N}$ parameters for five parameter model.

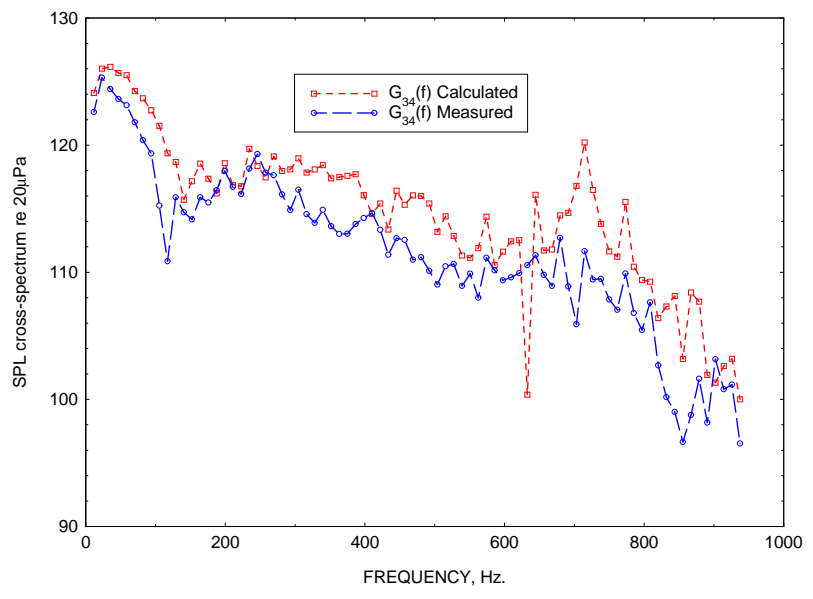

(b) Cross-spectrum magnitude between 100 and 110 Degree microphones at 150 feet using five parameter model.

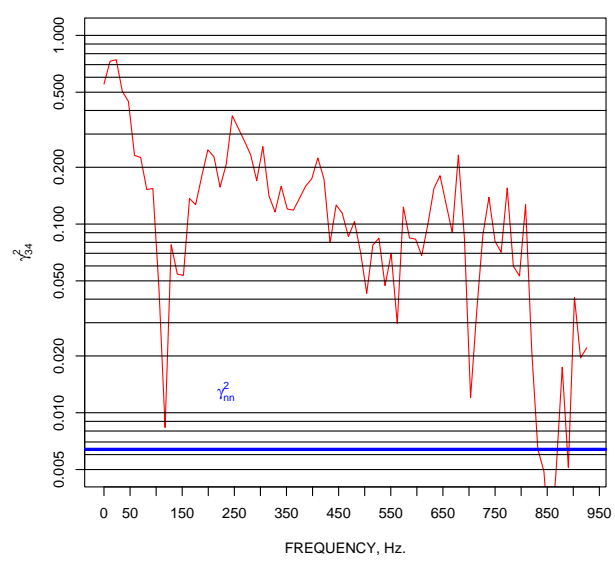

(d) Coherence between 100 and 110 Degree microphones at 150 feet

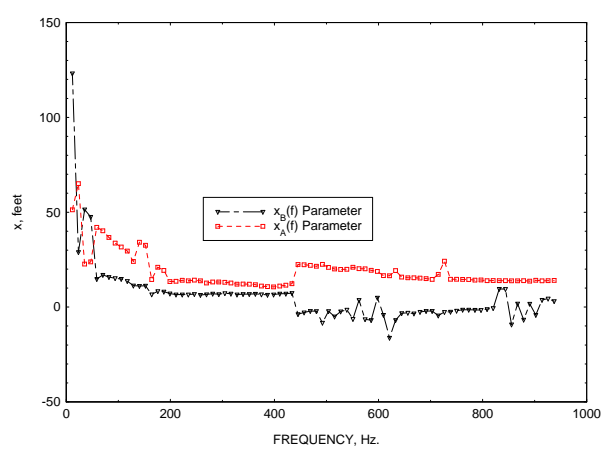

(f) $\quad x_{A}$ location parameter and $x_{B}$ location parameters for five parameter model.

Figure 6. 1900 rpm.(N1 Corr.) 


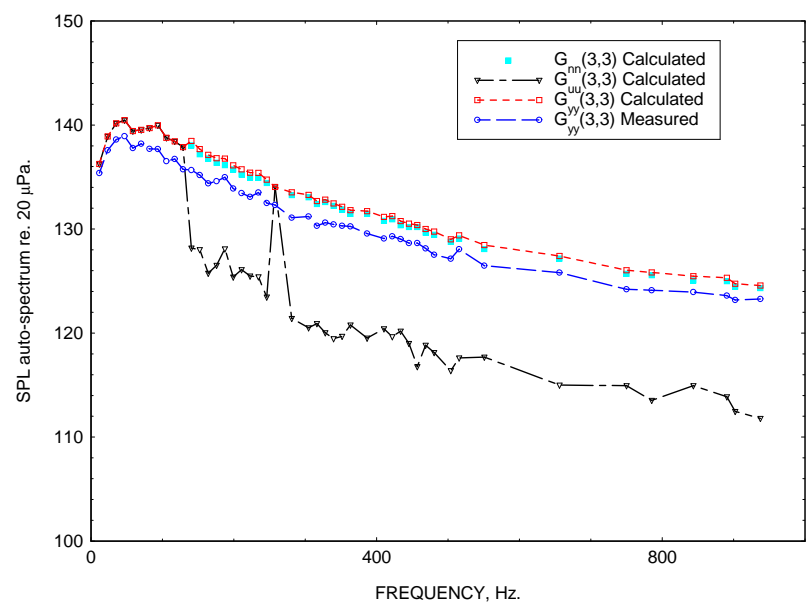

(a) Auto-spectrum 100 Degree microphone at 150 feet using three parameter model.

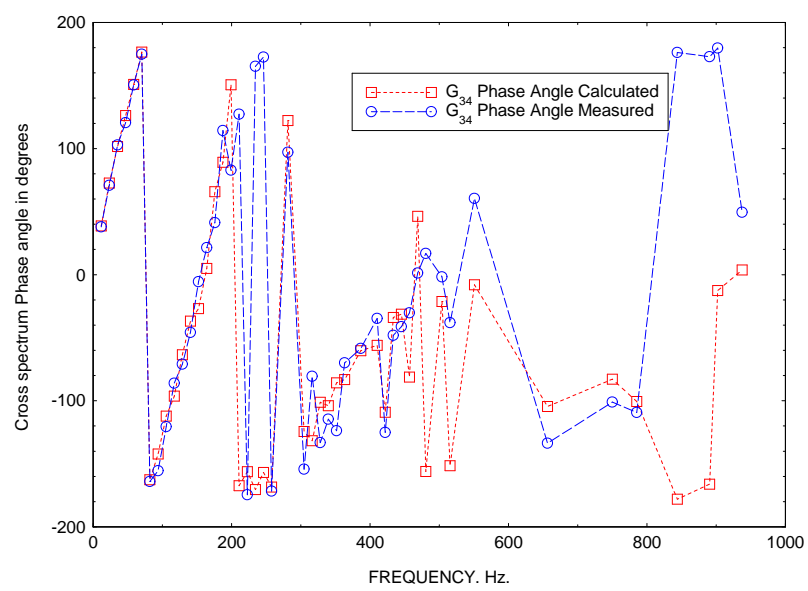

(c) Cross-spectrum phase angle between 100 and 110 Degree microphones at 150 feet using three parameter model.

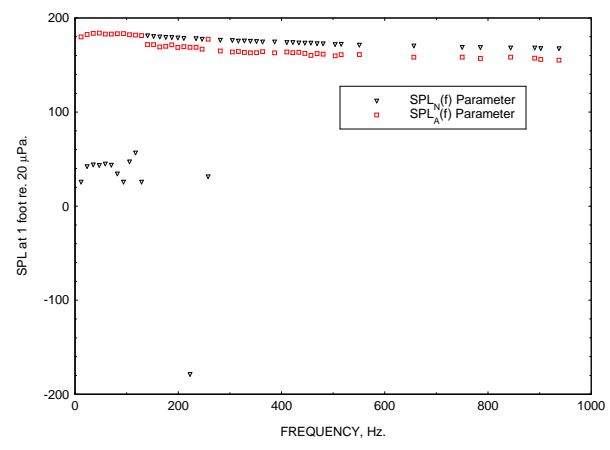

(e) $S P L_{A}$ and $S P L_{N}$ parameters for three parameter model.

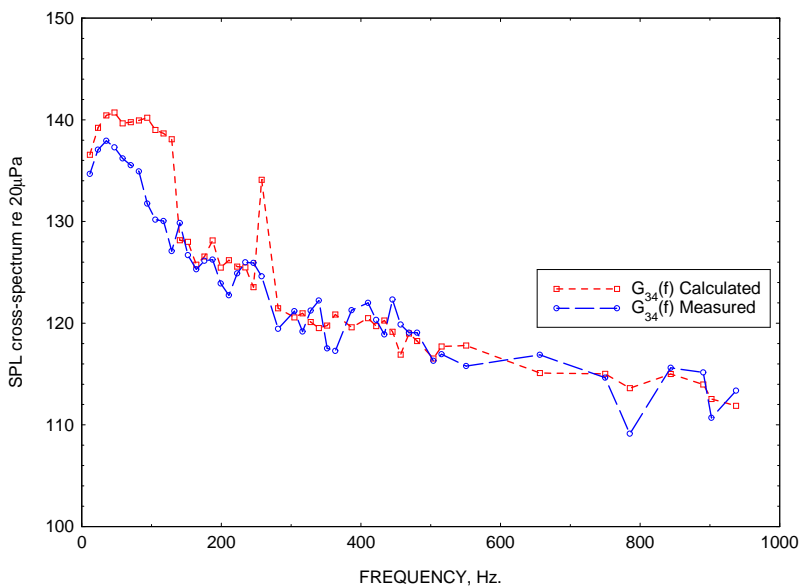

(b) Cross-spectrum magnitude beteen 100 and 110 Degree microphones at 150 feet using three parameter model.

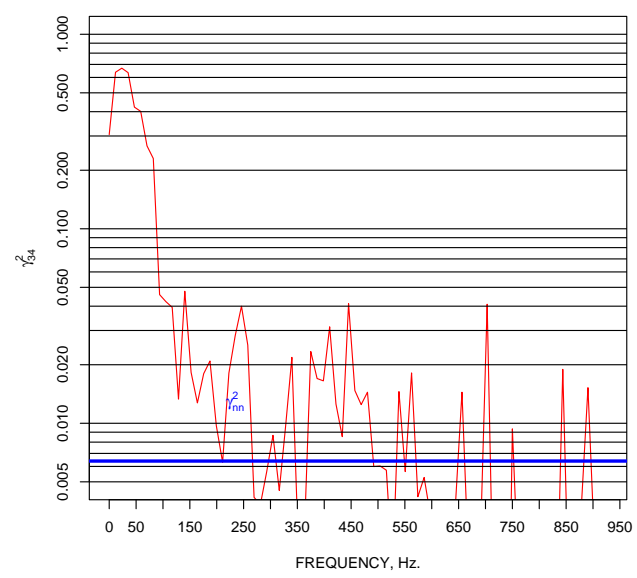

(d) Coherence between 100 and 110 Degree microphones at 150 feet

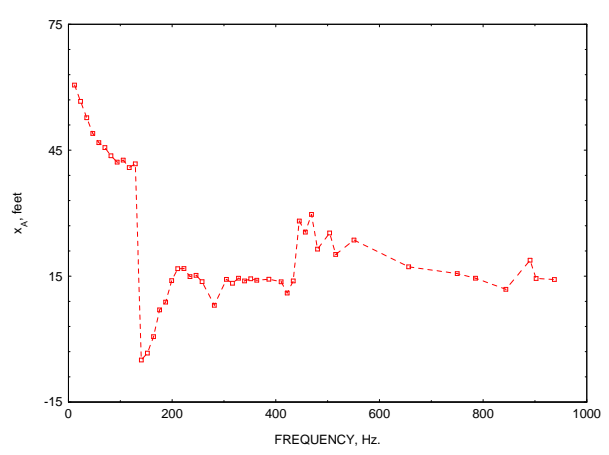

(f) $x_{A}$ location parameter for three parameter model.

Figure 7. 2743 rpm. (N1 Corr.) 


\section{References}

${ }^{1}$ Jeffrey Hilton Miles. Aligned and unaligned coherence: A new diagnostic tool. AIAA-2006-0010, NASA/TM-2006-214112,
January 2006.
${ }^{2}$ Jeffrey Hilton Miles. Validating coherence measurements using aligned and unaligned coherence functions. AIAA-2006-
1389, NASA/TM-2006-214113, January 2006.
surements. AIAA-2006-2581, May 2006.
s Julius S. Bendat and Allan G. Piersol. Measurement and Analysis of Random Data. John Wiley \&Sons, 1966.
${ }^{5}$ Julius S. Bendat and Allan G. Piersol. Random Data: Analysis and Measurement Procedures. John Wiley \&Sons, 1971.
${ }^{6}$ Julius S. Bendat and Allan G. Piersol. Engineering Applications of Correlation and Spectral Analysis. John Wiley \&Sons, 1980.

${ }^{7}$ Allen M. Karchmer. Identification and measurement of combustion noise from a turbofan engine using correlation and coherence techniques. NASA TM-73747, 1977.

${ }^{8}$ A.M. Karchmer, M. Reshotko, and F.J. Montegani. Measurement of far field combustion noise from a turbofan engine using coherence functions. AIAA Paper 77-1277,NASA TM-73748, Oct. 1977.

${ }^{9}$ J. Y. Chung, Malcolm J. Crocker, and James F. Hamiton. Measurement of frequency response and the multiple coherence function of the noise-generation system of a diesel engine. J. Acoust. Soc. Am., 58 No. 3:636-642, September 1975.

${ }^{10} \mathrm{~J}$. Y. Chung. Rejection of flow noise using a coherence function method. J. Acoust. Soc. Am., 62 No. 2:388-395, August 1977.

${ }^{11}$ Eugene A. Krejsa. New technique for the direct measurement of core noise from aircraft engines. Technical Report TM-82634, NASA, 1981.

${ }^{12}$ Belur N. Shivashankara. High bypass ratio engine noise component separation by coherence technique. J. Aircraft, 20 No. 3:236-242, March 1983. AIAA 81-2054, Aeroacoustics Conference, 7th, Palo Alto, CA Oct. 5-7, 1981.

${ }^{13}$ J.S. Hsu and K. K. Ahuja. A coherence-based technique to separate ejector internal mixing noise from farfield measurements. AIAA-98-2296, June 1998.

${ }^{14}$ R. W. Stoker, K. K. Ahuja, and J. HJsu. Separation of wind-tunnel background noise and wind noise from automobile interior measurements. AIAA-96-1763, May 1996.

${ }^{15}$ A. Michalke, F. Arnold, and F. Holste. On the coherence of the sound field in a circular duct with uniform mean flow. Journal of Sound and Vibration, 190 No. 2:261-271, 1996.

${ }^{16}$ Tomoyuki Minami and K. K. Ahuja. Five-microphone method for separating two different correlated noise sources from far field measurements contaminated by extraneous noise. AIAA 2003-3261, May 2003.

${ }^{17}$ S.P.Parthasarathy, R.F.Cuffel, and P.F.Massier. Separation of core noise and jet noise. AIAA Journal, 18 No. 3:256-261, 1980. AIAA-79-0589.

${ }^{18}$ Vincent Tesson. Experimental Investigation of Jet Noise and Core Noise Using a Small Gas Turbine Engine. A master of science thesis in aerospace engineering, The Pennsylvania State University, Department of Aerospace Engineering, August 2002.

${ }^{19}$ Vincent Tesson. Experimental investigation of jet noise and core noise using a small gas turbine engine. AIAA-2002-2558, June 2002 . 2002.

${ }^{20}$ Richard P. Brent. Algorithms for Minimization Without Derivatives. Prentice-Hall,1973;Dover Pulications, 2002, 1973,

${ }^{21}$ M. J. D. Powell. An efficient method of finding the mibnimum of a function of several variables without calculating derivatives. Computer Journal, 7 No. 2:155-162, July 1964.

${ }^{22}$ M. S. Shapiro and M. Goldstein. A collection of mathematical computer routines. Technical Report NYU-1480-14, New York University, February 1965.

${ }^{23}$ James L. Kuester and Joe H. Mize. Optimization Techniques with Fortran. McGraw-Hill, 1973.

${ }^{24}$ Samuel D. Stearns and Ruth A. David. Signal Processing Algorithms Using Fortran and C. PTR Prentice-Hall, Inc., 1993.

${ }^{25}$ G. Clifford Carter. Receiver operating characteristics for a linearly thresholded coherence estimation detector. IEEE Transactions on Acoustics, Speech, and Signal Processing, ASSP-25:90-92, February 1977.

${ }^{26}$ G. Clifford Carter. Coherence and time dealy estimation. Proceedings of the IEEE, 75 No. 2:236-255, February 1987.

${ }^{27}$ DM Halliday, JR Rosenberg, AM Amjad, P Breeze, BA Conway, and SF Farmer. A framework for the analysis of mixed time series/point process data-theory and application to the study of physiological tremor. Prog. Biophys Mol Biol, 64 No.:237-278, 1995.

${ }^{28}$ David R. Brillinger. Time Series Data Analysis and Theory -Expanded Edition. Holden-Day, 1981. ISBN:0-8162-1150-7.

${ }^{29}$ Allan Piersol. Time delay estimation using phase data. IEEE Transactions on Acoustics, Speech, and Signal Processing, ASSP-29 No. 3:471-477, June 1981.

${ }^{30}$ Philip M. Morse and K. Uno Ingard. Theoretical Acoustics. McGraw-Hill Book Company, 1968. 
Public reporting burden for this collection of information is estimated to average 1 hour per response, including the time for reviewing instructions, searching existing data sources, gathering and maintaining the data needed, and completing and reviewing the collection of information. Send comments regarding this burden estimate or any other aspect of this collection of information, including suggestions for reducing this burden, to Washington Headquarters Services, Directorate for Information Operations and Reports, 1215 Jefferson Davis Highway, Suite 1204, Arlington, VA 22202-4302, and to the Office of Management and Budget, Paperwork Reduction Project (0704-0188), Washington, DC 20503.

\begin{tabular}{|l|l|l|}
\hline 1. AGENCY USE ONLY (Leave blank) & $\begin{array}{c}\text { 2. REPORT DATE } \\
\text { May } 2006\end{array}$ & $\begin{array}{r}\text { 3. REPORT TYPE AND DATES COVERED } \\
\text { Technical Memorandum }\end{array}$ \\
\hline
\end{tabular}

4. TITLE AND SUBTITLE

5. FUNDING NUMBERS

Procedure for Separating Noise Sources in Measurements of Turbofan Engine Core Noise

6. AUTHOR(S)

Jeffrey Hilton Miles

7. PERFORMING ORGANIZATION NAME(S) AND ADDRESS(ES)

National Aeronautics and Space Administration

John H. Glenn Research Center at Lewis Field

Cleveland, Ohio 44135-3191

WBS 561581.02.08.03

National Aeronautics and Space Administration

Washington, DC 20546-0001

8. PERFORMING ORGANIZATION REPORT NUMBER

E-15627

\section{SPONSORING/MONITORING AGENCY NAME(S) AND ADDRESS(ES)}

10. SPONSORING/MONITORING AGENCY REPORT NUMBER

NASA TM-2006-214352

AIAA-2006-2580

\section{SUPPLEMENTARY NOTES}

Prepared for the 12th Aeroacoustics Conference cosponsored by the American Institute of Aeronautics and Astronautics and Confederation of European Aerospace Societies, Cambridge, Massachusetts, May 8-10, 2006. Responsible person Jeffrey Hilton Miles, organization code RTA, 216-433-5909.

12a. DISTRIBUTION/AVAILABILITY STATEMENT

12b. DISTRIBUTION CODE

Unclassified - Unlimited

Subject Category: 35

Available electronically at http://gltrs.grc.nasa.gov

This publication is available from the NASA Center for AeroSpace Information, 301-621-0390.

13. ABSTRACT (Maximum 200 words)

The study of core noise from turbofan engines has become more important as noise from other sources like the fan and jet have been reduced. A multiple microphone and acoustic source modeling method to separate correlated and uncorrelated sources has been developed. The auto and cross spectrum in the frequency range below $1000 \mathrm{~Hz}$ is fitted with a noise propagation model based on a source couplet consisting of a single incoherent source with a single coherent source or a source triplet consisting of a single incoherent source with two coherent point sources. Examples are presented using data from a Pratt \& Whitney PW4098 turbofan engine. The method works well.

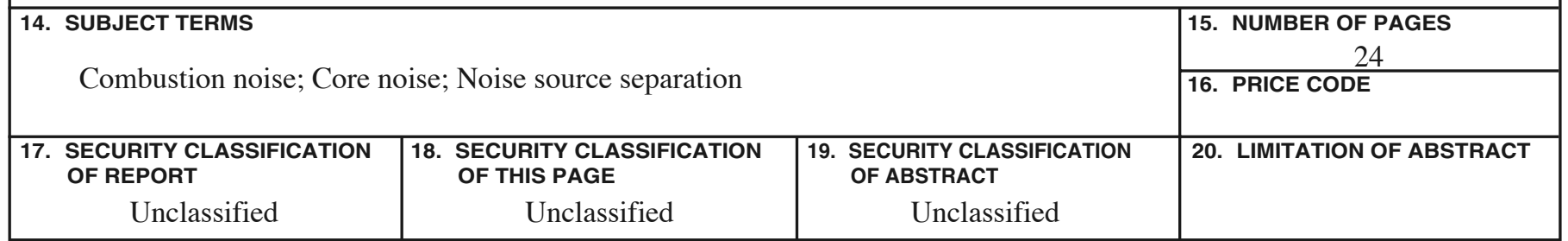



